J. Qureshi, and J. T. MOTTRAM, 'Response of beam-of-column web cleated joints for pultruded frames,' Journal of Composites for Construction, http://ascelibrary.org/doi/abs/10.1061/(ASCE)CC.1943-5614.0000392?af=R\&

\title{
RESPONSE OF BEAM-TO-COLUMN WEB CLEATED JOINTS FOR FRP PULTRUDED MEMBERS
}

Jawed Qureshi*, Research Fellow, Civil Research Group, School of Engineering, University of Warwick, Coventry, CV4 7AL, UK. Email: J.Qureshi@warwick.ac.uk

J Toby Mottram, Professor, Civil Research Group, School of Engineering, University of Warwick, Coventry, CV4 7AL, UK. Email: J.T.Mottram@warwick.ac.uk

* Corresponding author

\section{ABSTRACT}

Physical testing is used to characterise the structural properties of beam-to-column joints, comprising pultruded Fibre Reinforced Polymer (FRP) H-shapes of depth $203 \mathrm{~mm}$, connected by $128 \mathrm{~mm}$ long web cleats and two M16 bolts per leg. Testing is performed on two batches of nominally identical specimens. One batch had web cleats of pultruded FRP and other had structural steel. The structural behaviour of the joints is based on their moment-rotation responses, failure modes, and serviceability vertical deflection limits. Joints with FRP cleats failed by delamination cracking at top of cleats, and when cleats were of steel the FRP failure occurred inside the column members. Neither failure mode is reported in the design manuals from pultruders. At the onset of FRP damage it was found that the steel joints were twice as stiff as the FRP joints. Based on a characteristic (damage) rotation, calculated in accordance with Eurocode 0, the serviceability deflection limits are established to be span/300 and span/650 for the joints with FRP and steel cleats, respectively. This finding suggests that appropriate deflection limits, in relation to cleated connections, should be proposed in manufactures' design manuals and relative design standards and design codes. Failure to address the serviceability, by the Engineer of Record could lead to unreliable designs.

Keywords: Web cleats; pultruded joints; damage onset; moment-rotation response; deflection limit. 


\section{INTRODUCTION}

36 The traditional structural materials of stone, timber, steel and concrete have historical presence in construction. Although steel and reinforced concrete have emerged to be the leading materials it is recognized that when exposed to a chemically aggressive environment they are both susceptible to degradation and deterioration over time. Construction is responsible, in 2012, for almost a third of the global carbon emissions. In order to minimise the ecological impact on the built environment, there is a need to promote and develop the use of structural materials with a sustainable credibility. Fibre Reinforced Polymer (FRP) is such a construction material possessing high strength, lightweight, improved chemical and corrosion resistance, and of equal importance, a low (ecological) impact (Daniel 2003). FRP is a two-part composite material (Bank 2006) comprising of high strength (often continuous) fibres embedded in a lower strength polymer based matrix. Members of FRP have been used in primary structural engineering applications for more than two decades (Bank 2006). Due to quicker installation and an expected durable performance, FRP can be the cost-effective structural material in applications such as, cooling towers, chemical plants and railway footbridges. However, a major hurdle to the wider usage of FRP components is a lack of recognised and verified structural design guidance.

Pultrusion is the cheapest composite manufacturing process for the continuous production of FRP thin-walled shapes. One category of pultruded profiles possess the same cross-sectional shapes (I, H, Leg-angle, channel, box, etc.) as found in structural steelwork, but standard profiles of FRP have very different mechanical and structural properties (Bank 2006). They consist of E-glass fibre reinforcement having layers of unidirectional rovings and continuous mats in a thermoset resin based matrix, usually having the polymer of polyester or vinylester. Having a weight of only $25 \%$ of steel FRP materials are lightweight. Like steel, the tensile strength in the longitudinal direction is more than $200 \mathrm{MPa}$. The longitudinal modulus of elasticity lies in the range $20-30 \mathrm{GPa}$, which is $10-6$ times lower than steel. The elastic modulus in the transverse direction is 0.3 of the longitudinal value (Anonymous 2013a; 2013b; 2013c). 
63 It is recognized that as much as $50 \%$ of the cost of executing frame structures can be for the 64 fabrication of connections and joints. Current practice is to construct pultruded FRP frames that are 65 of simple (non-swayed braced) construction. Simple joint details are expected to behave as nominally pinned when subjected to moment. They must be capable of transmitting internal forces without developing significant moments. Furthermore, they need to rotate sufficiently to meet the severability vertical deflection limits for the simply supported beam subjected to a uniformly distributed load. Joint details commonly have web cleats (or clip angles) that connect the beam and column members with conventional steel bolting. Information found in the design manuals from two American pultruders (Anonymous 2013a; 2013b) are for the web cleats to be fabricated from pultruded FRP equal leg-angle. Design strengths are based on a (relatively) high factor of safety of 4 in an Allowable Stress Design (ASD) approach (Anonymous 2013a; 2013b). Because there are concerns (Mosallam 2011) that the fibre architecture in FRP cleats is inappropriate to resist prying action deformations an alternative material for cleating can be of structural steel.

The moment-rotation responses and properties of joints with pultruded members is characterised through full-sized physical testing (Bank et al. 1990; Bank et al. 1992; Bass and Mottram 1994; Mosallam et al. 1994; Qureshi and Mottram 2012), because theoretical and numerical methods cannot reliably analyse the initiation and progression of FRP material damage. Turvey and Cooper (2004) presented a review of 59 individual joint tests, out of which only two pairs of specimens had nominally identical joint details. Reported test results from the 1990s were therefore based on a batch with a single specimen. Due to lack of specimen repetition, the variability in a joint's rotational stiffness could not be statistically quantified to establish a characteristic value for design. Turvey (1997) developed an analytical treatment to utilise the inherent non-zero rotational stiffness of (simple) joints to quantify the increase in load carrying capacity of beam members. Utilizing the semi-rigid joint action he formulated closed-form equations for calculating vertical deflection that were functions of the joint's initial rotational stiffness $\left(S_{\mathrm{i}}\right)$. Inserting into these equations a value of $S_{\mathrm{i}}$ 
established from too few test results is going to be unreliable. To characterise the key joint properties for their variability it is necessary to conduct tests on batches with more nominally identical joints. One of the objectives of this paper is to report test results from two batches that can be statistically analysed to obtain information that can be used to prepare improved design guidelines for simple construction.

The moment-rotation $(M-\phi)$ response of beam-to-column joints with pultruded FRP web cleats have been investigated in previous studies. Bank, Mosallam and Gonsior (1990) were first to report experimental test results. They characterised one single-sided joint using $203 \times 203 \times 9.53 \mathrm{~mm}$ members and cleats (without dimensions) cut from a $152 \times 152 \times 12.7 \mathrm{~mm}$ leg-angle. At mid-depth of the double-sided cleating there was a single row of two $19 \mathrm{~mm}$ diameter FRP bolts. Mottram (1996) presented $M-\phi$ results from four double-sided joint tests (three of major axis and one for minor axis configurations) in an appendix to the EUROCOMP Design Code and Handbook. Two key findings from his work, using the same research methodology as for the test results reported in this paper, were that adhesive bonding cannot be used on its own, and there needs to be a gap of 6-12 $\mathrm{mm}$ between a beam-end and column face to accommodate 'free' rotation between the connected members. Two major and one minor axis joint test with leg-angle cleats and steel bolting and 254 mm deep members were conducted by Mottram and Zheng (1999a). The aim of this test series was to confirm the design guidance in the EUROCOMP appendix (Mottram 1996). A major concern of using cleats of FRP material was that the onset of delamination failure (Bank 2006) at the top of the cleating could occur before the simply supported beam achieves the serviceability vertical deflection limit of span/250, taken from EUROCOMP (Clarke 1996). Because many FRP structures are constructed for a chemically hostile environment, delamination fractures initiating under serviceability loading could have a serious detrimental effect on the service life. For this reason Mottram and Zheng (1999a) and Mosallam (2011) both recommended using other composite manufacturing processes to manufacture FRP connection components that should, without FRP failure, accommodate joint rotations in excess of $25 \mathrm{mrad}$. 
117 Owing to the uncertainty of having cleats of FRP it is known that fabricators can prefer steel for the

118 connection components. Pultruders provide no design guidelines (Anonymous 2013a; 2013b; 2013c)

119 when the cleating is of steel, and to establish their joint properties there are few test results too.

120 Mottram and Zheng (1999b) carried out two one-off tests for flange-cleated steel joints for study on

121 semi-rigid action. Turvey (2000) test series was with specimens having web, flange and web, and

122 flange only cleats of steel leg-angles. A shortcoming in the work by Turvey (2000) is that the beam

123 was connected directly to a relatively stiff steel support that (completely) eliminated the flexibility of

124 the pultruded FRP column; which is part of the joint zone (BS EN 1993-1-8:2005). Because of the

125 specific test configuration the measured joint stiffness would be too high. To reliably quantify joint

126 properties, it is essential to take into account the flexibility of the pultruded column. Characterisation

127 of a joint's properties using the test configuration and method in Mottram and Zheng (1999a; 1999b)

128 represents the construction of pultruded frames when there are no seismic actions.

129

130 The main objective of this paper is to study the $M-\phi$ responses of nominally pinned joints focusing on

131 two key test parameters. The first of these parameters is specimen repetition and the second is to have

132 web cleat material of either FRP or steel. One test batch will consist of five specimens having 10

133 joints and FRP cleating, and the second batch will have three specimens for six joints with steel

134 cleats. Using the batch results there will be a discussion on joint properties, moment-rotation

135 responses, failure modes, damage onset criteria and vertical deflection limit for Serviceability Limit

136 State (SLS) design. Finally, an important insight towards the preparation of design guidelines is 137 gained from an evaluation of the findings.

\section{TEST CONFIGURATION AND TEST PROCEDURE}

140 Figs. 1-4 illustrate the test configuration consisting of two back-to-back cantilever beams connected

141 to a central column. A pair of web cleats and steel bolts is used to connect each beam to the major-

142 axis of the column. The web cleat material is either pultruded FRP or structural grade steel. A joint is 
143

144

145

146

148

149

150

151

152

153

154

155

156

157

158

159

160

161

defined as the zone where two or more members are interconnected. For design purposes (BS EN 1993-1-8:2005) it is the assembly of all the basic components required to represent the behaviour during the transfer of the relevant internal forces and moments between the connected members. A beam-to-column joint consists of a web panel, from the column side, and either one connection (single sided joint configuration) or two connections (double sided joint configuration). The latter configuration is for the test configuration in Figs. 1-4 and so the joint moment $(M)$ is to be determined at the column's centroidal axis.

Each test specimen gives two joints, called the Left and the Right joint. Similar test arrangement has previously been used by Qureshi and Mottram (2012) and Mottram and Zheng (1999a; 1999b). The beams and columns are $1.5 \mathrm{~m}$ long and are of size $203 \times 203 \times 9.53 \mathrm{~mm}$ from the Pultex ${ }^{\circledR}$ SuperStructural 1525 series of Creative Pultrusions Inc (Pultex ${ }^{\circledR}$ pultrusion design manual 2013). From this pultruder's Design Manual (Anonymous 2013a) the shape's flexural strength is $228 \mathrm{MPa}$ and the second moment of area about the Major axis is $4.18 \times 10^{7} \mathrm{~mm}^{4}$. Based on conventional linear elastic beam theory the flexural moment of resistance for the section could be $94 \mathrm{kNm}$. For a laterally unrestrained beam the ULS mode of failure is likely to be local flange bucking. A lower bound estimate for the uniform compression stress for critical elastic local buckling can calculated from (is Equ. (6) in Mottram (2004a)):

$$
\sigma_{\mathrm{c}, \mathrm{cr}}=\frac{G_{\mathrm{LT}}}{\left(\frac{\mathrm{b}}{2 t_{\mathrm{f}}}\right)^{2}}
$$

162 In Equ. (1) $G_{\mathrm{LT}}$ is the in-plane shear modulus of the flange material, taken to be $4.0 \mathrm{GPa}, b$ is the

163 flange width of $203 \mathrm{~mm}$ and $t_{\mathrm{f}}$ is the flange thickness of $9.53 \mathrm{~mm}$. The critical local buckling stress $164\left(\sigma_{\mathrm{c}, \mathrm{cr}}\right)$ is $35 \mathrm{MPa}$ and using beam theory, again, the moment resistance of the section for local 165 buckling failure is $14.5 \mathrm{kNm}$. 
Standard size leg-angles are used to fabricate the web cleats, with the FRP angle at $75 \times 75 \times 9.53 \mathrm{~mm}$ and the steel at $75 \times 75 \times 10 \mathrm{~mm}$. The cleats are $128 \mathrm{~mm}$ long (Fig. 2) for the $203 \mathrm{~mm}$ deep beam member.

170

The 10 joints with pultruded FRP cleats are denoted by label Wmj203_2M16_FC and the six with steel cleats by Wmj203_2M16_ST. This joint labelling convention continues from that used by Qureshi and Mottram (2012) and Mottram and Zheng (1999a). Label Wmj203_2M16_FC specifies the joint as Web-cleated with a major axis column, $203 \times 203 \times 9.53 \mathrm{~mm}$ wide flange sections using a single row of 2 M16 bolts with pultruded FRP web Cleating. Similarly, the label Wmj203_2M16_ST

176 is used for the batch with STeel cleats.

177

\section{Connection detailing}

179

180

181

182

183

184

185

186

Fig. 2 shows a web cleated joint that corresponds to Detail 2 illustrated on Page 19-6 of the Strongwell Design Manual (Anonymous 2013b). This detailing satisfies the minimum requirements for bolted connection geometries as permitted in a standard under preparation (Anonymous 2013d). The detailing in the drawing has steel bolting and the provision of a $10 \mathrm{~mm}$ gap between the beam end and column flange. The gap, bolting, etc., in the Wmj203_2M16_FC and Wmj203_2M16_ST joint specimens are presented in Figs. 1-4.

Bolting has steel bolts of M16 grade 8.8 and $3 \mathrm{~mm}$ thick by $35 \mathrm{~mm}$ diameter steel washers. The length of the bolt shank in contact with FRP is plain to avoid any localised FRP failure due to bolt thread bearing stresses. In order to bring connected FRP panels into firm contact the bolts are tightened to the snug fit condition, which is achieved when the bolt or nut will not turn any further with the full effort of a construction worker using a standard hand wrench (Gorenc et al. 2005). Firm contact is defined as "the condition that exists on a faying surface when the plies are solidly seated against each other, but not necessarily in continuous contact" (Anonymous 2000). One important feature in these tests is that clearance hole size is kept minimal (on beam side) to ensure that joint rotation $(\phi)$ is 
194 dominated by prying action from the applied $M$ (Qureshi and Mottram 2012). To achieve this test

195 condition, precision holes of $16 \mathrm{~mm}$ diameters were drilled into the web cleats, and beams and

196 column members using a CNC machine with a geometric tolerance $\pm 0.1 \mathrm{~mm}$. Bolt clearance hole

197 could not be eliminated altogether because 'off the shelf' M16 bolts have a diameter in the range of

$198 \quad 15.6$ to $15.9 \mathrm{~mm}$.

199

200 The approach to bolt tightening used follows the guidance in Anonymous (2011). It also corresponds

201 to the description of what is 'snug-tight' in the well-known monograph for steel structures by Kulak

202 et al. (1987). The main reason for not using calibrated torque wrench is that the bolt torque will lie in

203 the range $\pm 30 \%$ of a mean value (Kulak et at. 1987). A second reason is that to ensure the same

204 (initial) clamping pressure in the bolted connection with changes in FRP material, FRP thicknesses,

205 bolt material, bolt sizes (diameter and pitch), washer type, etc, would require an extensive list of

206 specified bolt torques. This is not realistic for practice. Another important reason for not needing to

207 use a calibrated torque wrench is that FRP is a viscoelastic material, and as shown by Mottram

208 (2004b), the bolt tension will disappear (exponentially) with time, and might be reduced to half by

209 the end of a structure's service life. At the time of testing the frictional force that exists between the

210 connected FRP panels cannot therefore be known with certainty. Moreover, the test results, after

211 compensation for 'secondary' slippage, will not change if bolt tightening is lower or higher. It is

212 important to appreciate that the purpose of the research reported herein is to establish the onset of

213 damage in the FRP web cleats or members when the joint assembly gives the stiffest $M$ - $\phi$ response

214 that could exist.

216 Although the additional $\phi$ due to slippage (from having clearance holes) will be beneficial in the field

217 (Anonymous, 2013a; Anonymous 2013b), it cannot be guaranteed for the reason now explained. The

218 magnitude of slip rotation depends on where the bolts are placed in their holes. There could be

219 assemblies where bolting is positioned in such a way that no slip can occur before the joint

220 experiences its ultimate moment of resistance, which is defined by the maximum joint moment, $M_{\max }$. 
221 This worst case in the field was the justification for the slip rotation to be eliminated in the testing.

222 To minimise the contribution to joint rotation from slippage the clearance hole size was made

223 minimal for the beam side connections. For ease in assembling there is a clearance hole of $2 \mathrm{~mm}$ to

224 the bolting on the column side. The presence of clearance in the column connections does not 225 influence overall joint rotations.

\section{Loading Procedure}

228 As seen in Figs. 1 and 3 loading is applied, at a horizontal distance of $1.016 \mathrm{~m}$ from the centre of the

229 column, into the two beams by means of a hanger assembly. This moment lever arm distance is 230 controlled by the layout of the anchor points on a strong floor, which are $408 \mathrm{~mm}$ (16 in.) apart 231 (Mottram and Zheng 1999a). To ensure vertical alignment of the load it is transferred through a steel 232 ball bearing, of $12.7 \mathrm{~mm}$ diameter, located in a hemi-spherical steel socket at the centre of the two 233 steel loading plates. For the Left and Right joints the applied load is measured through tension load 234 cells having a capacity of $9 \mathrm{kN}$ with a resolution of $\pm 0.01 \mathrm{kN}$. A rocker base fixture is used 235 underneath the column member to alleviate effects of flexure, and to accommodate free in-plane 236 rotations. Two independent manual hydraulic pumps are used to operate the two tension jacks. It is 237 operationally difficult to guarantee equal pressure (load) to the Left and Right sides. Even if the 238 applied load is not equal, the rocker base fixture at the bottom of the column ensures the same joint 239 moment $(M)$ on both sides. Fig. 1 shows the longitudinal centreline of the two beams is at a vertical 240 distance of $1094 \mathrm{~mm}$ from the base of the column. This distance is dictated by the height of hydraulic 241 tension jacks and is enough to allow a downward stroke of $150 \mathrm{~mm}$ on the jacks.

243 The specimens are loaded under load control in increments of $0.1 \mathrm{kN}$. For visual inspection of the 244 joint, a time interval of 5 minutes is maintained throughout the loading regime. This time gap is 245 essential to observe any cracking and progressive damage. Load, rotation and displacement readings 246 are taken instantly after load is applied and after a time lapse of 5 minutes. The loading increments 247 are continued until rotation increases rapidly without a corresponding increase in $M$ or when further 
loading would cause instability of the specimen. To observe permanent rotations, the specimens were loaded and unloaded after overall rotations of about 10, 20 and 30 mrad.

250

\section{Instrumentation}

252 Joint properties are measured using the instrumentation shown in Figs. 3 and 4. To record the beam 253 rotations the inclinometers $\mathrm{C} 1$ and $\mathrm{C} 3$ are positioned $100 \mathrm{~mm}$ from the connected end of the Left side 254 and Right side, respectively. The rotation of the column is measured by $\mathrm{C} 2$ placed at the centre of the 255 joint, and the Left and Right joint rotations are determined from the difference between the beam and 256 column rotations. Relative slip between a pair of cleats and the beam is measured via two 257 displacement transducers, labelled in Fig. 4 as LTL and LBL, and LTR and LBR. The first letter in 258 LTL is for the centre-to-centre vertical distance of $64 \mathrm{~mm}$ between two horizontal transducers, and 259 the second and third letters are for the Top of cleat and for the Left-sided joint. Rotations are 260 measured to a resolution of $0.02 \mathrm{mrad}$ (linear to $\pm 1 \%$ over a $10^{\circ}$ range) and displacements to \pm 0.01 $261 \mathrm{~mm}$. Slip rotation due to relative horizontal slip between a pair of web cleats and the beam web has to 262 be subtracted from the measured joint rotation in order to obtain the required $\phi$. This 'secondary' slip 263 rotation $\left(\phi_{\text {slip }}\right)$ is calculated from:

$$
\phi_{\text {slip }}=\tan ^{-1}\left(\frac{l b-l t}{l}\right) \times 1000 \quad \quad(\mathrm{mrad})
$$

where $l t$ and $l b$ are the horizontal slips measured by the displacement transducer pair of either LTL and LBL for Left joint or LTR and LBR for Right joint.

When web cleats are of FRP, failure is by way of delamination cracking at top of cleats near the fillet radius (Mottram and Zheng 1999a; Mosallam 2011; Qureshi and Mottram 2012). With change of material to steel, the web cleating in itself is not the weak link. The structural steel has characteristic

271 yield strength of $275 \mathrm{MPa}$ that is many times higher than the through-thickness tensile strength of 272 FRP and the modulus of elasticity is 10-20 times higher. These significant differences in material 273 properties ensure that the steel cleating, of $10 \mathrm{~mm}$ thickness, cannot fail first under the prying action. 
274 The resulting tension from the joint moment force acting at top bolt level can be expected to produce

275 significant flexural deformation in the column flange outstands. In order to monitor these outstand 276 deformations the change in column depth, given by $\left(h_{\text {prying }}-h\right)$ is measured after each load 277 increment. Fig. 2 defines $h$ to be the undeformed depth of the column member and $h_{\text {prying }}$ to be its 278 deformed depth. Throughout the testing $h_{\text {prying }}$ is measured both at the top and bottom bolt levels.

\section{RESULTS AND DISCUSSION}

The modes of failure, joint properties and moment-rotation $(M-\phi)$ responses will be presented in a discussion of results in two parts. The first part is for the joint tests with FRP cleats, while the second part is for the tests with steel cleats. Joint properties that are dependent on $\phi$ have been compensated for slip rotation $\phi_{\text {slip }}$ using Equ. (2). Tables 1 and 2 report the joint properties for the 10 Wmj203_2M16_FC joints and the six Wmj203_2M16_ST joints. Each specimen has a Left and Right-sided joint and this is identified in the tables. When two values from a single specimen are given in the discussion the first will always be for the Left-sided joint and the second for the Rightsided joint. To highlight the minimum and maximum measurements they are given in bold text. Column (1) gives the specimen label using the scheme introduced earlier in the paper. Columns (2) to (4) report the linear joint properties of initial moment $\left(M_{\mathrm{i}}\right)$, initial joint rotation $\left(\phi_{\mathrm{i}}\right)$ and initial joint stiffness $S_{\mathrm{i}}\left(=M_{\mathrm{i}} / \phi_{\mathrm{i}}\right)$. As soon as the $M-\phi$ response is observed to go non-linear $M_{\mathrm{i}}$ and $\phi_{\mathrm{i}}$ are established. The same three properties at (FRP material) damage onset of $M_{\mathrm{j}}, \phi_{\mathrm{j}}$ and $\left(S_{\mathrm{j}}=M_{\mathrm{j}} / \phi_{\mathrm{j}}\right)$ are given in columns (5) to (7). In this study subscript ' $\mathrm{j}$ ' is for the key properties of a joint immediately after initiation of damage onset due to FRP failure. A specific definition for damage onset is to be given for both cleat materials. Maximum joint properties of $M_{\max }$ and $\phi_{\max }$ are given by columns (8) to (9). Mean and coefficient of variation (CV) for the eight joint properties are given at the bottom of the tables. 
301 Failure patterns and a definition for damage onset are discussed first, followed by an evaluation of 302 the joint properties presented in Table 1 , the $M-\phi$ curves and the relationship between damage 303 rotation and SLS vertical deflection limits. Fig. 5 has four parts, with (a) and (b) for the undeformed 304 $(\phi=0)$ Left and Right joints in Wmj203_2M16_FC1.3 with (c) and (d) for these joints after $\phi_{\max }$ (column (9) in Table 1) had been applied.

An appropriate definition for onset of FRP failure is crucial in establishing the serviceability rotation for design of the beam section in bending. For joints with FRP cleats it is defined as a point on the $M$ $\phi$ where hairline delamination cracking first becomes visible at top of cleating and near the fillet radius. This failure pattern is well-known when using pultruded leg-angles for the web cleats (Bank et al. 1990; Qureshi and Mottram 2012). Using a dentist's mirror to view the top surface clearly, the 312 photograph in Fig. 6 shows the failure mode on testing Wmj203_2M16_FC1.4. It is noted that initiation of the delamination cracks can happen on either side of the junction between a pair of legs. At each load increment, careful observations were made to detect the extent of FRP damage progression. As can be seen in Figs. 5(c) and 5(d) the increase in $M$ from $M_{\mathrm{j}}$ to $M_{\max }$ caused the FRP legs to become visually separated from column flanges. At this stage of the test, existing cracks are widened and the new delamination cracks are formed. Loud, and audible noises signalling crack 318 propagation following an instant increase in $\phi$, without corresponding enhancement in $M$, were signs 319 of impending ultimate failure. The ultimate failure of all 10 joints with FRP cleats was due to 320 excessive delamination damage. Because the positioning of layers of E-glass reinforcement are not 321 constant through the leg-angle's thickness either the Left or Right cleat pair experienced more FRP 322 damage, and thus joint rotation, than the other. This helps to explain why $\phi_{\max }$ in column (9) of Table 3231 for the Left and Right-sided joint pair is often significantly different. This difference in rotation can 324 be seen by comparing in Figs. 5(c) and 5(d) the deformations of the joints in specimen 325 Wmj203_2M16_FC1.3. 
327 The 10 entries in column (2) of Table 1 inform us that the $M$ - $\phi$ response remains linear up to a mean $328 M_{\mathrm{i}}$ of $0.32 \mathrm{kNm}$ with a Coefficient of Variation $(\mathrm{CV})$ of $12 \%$. The range for $M_{\mathrm{i}}$ is for a minimum of $3290.26 \mathrm{kNm}$ to a maximum of $0.35 \mathrm{kNm}$. Initial rotations $\left(\phi_{\mathrm{i}}\right)$ in column (3) are seen to range from a 330 minimum of $3.2 \mathrm{mrad}$ to a maximum of $5.2 \mathrm{mrad}$, with mean and CV of $4.2 \mathrm{mrad}$ and $16 \%$. From

331 column (4) the minimum and maximum initial joint rotational stiffnesses $\left(S_{\mathrm{i}}\right)$ are 63 and $87 \mathrm{kNm} / \mathrm{rad}$.

332 The mean $S_{\mathrm{i}}$ of $76 \mathrm{kNm} / \mathrm{rad}$ has a $\mathrm{CV}$ of $9 \%$. Columns (8) and (9) give $M_{\max }$ and $\phi_{\max }$ and their means 333 are $1.0 \mathrm{kNm}$ and $43 \mathrm{mrad}$ respectively. It is found that the mean $M_{\max }$ of $1 \mathrm{kNm}$ is $<7 \%$ of the lower 334 bound estimate for the ULS moment of resistance $(14.5 \mathrm{kNm})$ due to elastic local (flange) buckling. 335 This result informs us that in accordance with Clause 5.2.3.2(3) in Eurocode 3 Part 1-8 (BS EN 1993336 1-8:2005) the FRP cleated joints can be classified as nominally pinned by strength. In terms of the 337 flexural moment of resistance $(94 \mathrm{kNm})$ for the $203 \times 203 \times 9.53 \mathrm{~mm}$ shape the $M_{\max }(1 \mathrm{kNm})$ is just 338 above $1 \%$.

Whilst the $M_{\max }$ from the batch of 10 joints has a relatively low CV at $4 \%$ there is a very high CV of $34132 \%$ with $\phi_{\max }$. Two reasons can be given for this significant variation in maximum rotation. One of 342 these is that it depends on when the testing was stopped, and the termination criterion used was either 343 excessive FRP failure or when there could be instability of the specimen. The second of the reasons 344 existed when either the Left or Right joint had rotated considerably more than the other. The 345 difference in $\phi_{\max }$ is seen to be associated to a significantly different level of delamination cracking 346 on the two sides, as seen in Figs. 5(c) and 5(d).

348 Figs. 7 and 8 present the $M$ - $\phi$ curves for Wmj203_2M16_FC1.3, with and without the slip rotation 349 compensated for. In these figures, the Left joint's $M-\phi$ is represented by a solid line curve and the 350 Right joint by a dashed line curve. On each curve a solid circle symbols is used to indentify $M_{\mathrm{j}}$ and $351 \phi_{\mathrm{j}}$. The saw-tooth shape to the $M$ - $\phi$ curves is due to taking sets of readings immediately after load 
application and 5 minutes later, before the next increment is applied. The measured reduction in $M$ is

353 because the joints are undergoing relaxation with time. The test results indicate that response remains

354 linear elastic until web cleats start to delaminate causing loss of joint stiffness and increased local

355 deformation. Beyond a moment of $0.35 \mathrm{kNm}$ the $M-\phi$ response goes non-linear. For this specific joint

356 pair the value of $\phi$ at ultimate failure on Left side is double that on Right side. It was observed that

357 the Left joint experienced more FRP progressive failure and this observation can be explained by the

358 inhomogeneous nature of the pultruded leg-angle, as discussed earlier. Figs. 5(a) and 5(b) show the

359 undeformed Left and Right joints, and Figs. 5(c) and 5(d) are for when they were fully deformed. It is

360 very clear from the latter two images that the Left side rotated most in order to maintain the same

361 level of $M$. At damage onset, the secondary slip rotations for specimen Wmj203_2M16_FC1.3 were

3620.9 and $5.5 \mathrm{mrad}$. This leads to an artificially higher $\phi_{\mathrm{j}}$ (for damage onset) of 14.5 and $20 \mathrm{mrad}$ and

363 different $M-\phi$ curves in Figs. 7 and 8 for what are nominally identical joints. When the slip rotation

$364\left(\phi_{\mathrm{slip}}\right)$ is compensated for in Fig. 8, the two joints now give the same trends and similar $\phi_{\mathrm{s}}$ at 13.6 and

$36514.4 \mathrm{mrad}$. To be able to propose improved design guidance the comparison of the $M-\phi$ curves in

366 Figs. 7 and 8 justifies why slip rotation had to be accounted for so that the reported joint responses

367 are primarily due to prying action deformation in the cleated connections.

369 As can be seen from the plots in Figs. 7 and 8 that specimen Wmj203_2M16_FC1.3 was thrice 370 unloaded and reloaded to assess the extent of permanent deformation in the joints. This next 371 discussion will be specific to the $M-\phi$ results reported in Fig. 8. First unloading took place when $\phi$ 372 first attained $10 \mathrm{mrad}$, before FRP damage had appeared. Measured permanent rotations were 3.5 $373 \mathrm{mrad}$ on both joint sides. Second unloading stage was taken when $\phi$ was about $20 \mathrm{mrad}$ and this gave 374 permanent rotations of 7.5 and $8.5 \mathrm{mrad}$. When the planned third unloading stage of $30 \mathrm{mrad}$ was 375 reached the jack operator could no longer control the rotation, and the $40 \mathrm{mrad}$ on the Left side was $37616 \mathrm{mrad}$ higher than on the Right side. Unloading from joint rotations of 40 and 26 mrad resulted in 
permanent rotations of 22 and $11 \mathrm{mrad}$. On unloading from $M_{\max }$ the permanent joint rotation was significant at 43 and $13 \mathrm{mrad}$, respectively.

A SLS is the condition beyond which a whole structure or part thereof fails to satisfy its intended purpose under unfactored design loading, but has not reached an ultimate limit state (BS EN 1990:2002). For a simply supported steel beam having a span of $L$ subjected to a uniformly distributed load, a common deflection limit is $L / 360$. This is for the structural situation where beam members are carrying plaster or other brittle finish, and is found for example, in the NA to BS EN 1993-1-1:2005. For design of beams the Design Manual from Creative Pultrusions Inc. has allowable uniform load tables for a number of shapes (Anonymous 2013a). The table on page 29 of Chapter 4 is specific to the Pultex ${ }^{\circledR}$ SuperStructural Wide Flange section of size $203 \times 203 \times 9.53 \mathrm{~mm}$ (Pultex ${ }^{\circledR}$ pultrusion design manual 2013)used in the testing. It presents a number of vertical deflection limits that are acceptable for this shape when used as a simply supported beam member. The table allows for a maximum deflection limit of $L / 150$ when $L$ ranges from 5 to $7.25 \mathrm{~m}$. Moreover, it gives uniform distributed loads for the deflection limits of $L / 180$ (3.25 to $7.25 \mathrm{~m}), L / 240$ (2.75 to $7.25 \mathrm{~m})$ and $L / 360$ ( 2.5 to $7.25 \mathrm{~m})$. The values in brackets are for the span range specific to the deflection limit. There are no notes with the Creative Pultrusions tables to recommend when the different limits are to be adopted. Creative Pultrusions lets this task up to the engineer of Record. It is noteworthy that more than a single limit could be required to account for different structural situations, environmental conditions and/or loading cases. Irrespective of the FRP beam's size, the EUROCOMP Design Code and Handbook (Clarke 1996) recommends a SLS deflection limit of $L / 250$. These different limits for vertical deflection show that work is needed to find out a reliable SLS design approach.

The bar chart in Fig. 9 presents the $\phi_{\mathrm{j}}$ s from testing the 10 joints having FRP cleats (see column (6) in Table 1). Higher than the measured $\phi_{\mathrm{J}} \mathrm{S}$, the 'SLS' deflection limit of $17.8 \mathrm{mrad}$ (for $L / 180$ ) from Creative Pultrusions Inc. is given by the horizontal dashed line. Note that when determining the end rotation (e.g. $17.8 \mathrm{mrad}$ ) for a deflection limit (e.g., L/180) the Pultruded FRP beam member is 
assumed to be shear rigid and the properties for the $203 \times 203 \times 9.53 \mathrm{~mm}$ shape are taken from the Pultex ${ }^{\circledR}$ SuperStructural table of mechanical properties in Chapter 3 of Anonymous (2013a). Using the expression Mean $-1.72 \times$ SD, from Annex D of Eurocode 0 (BS EN 1990:2002), and assuming the $\mathrm{CV}$ is known, the characteristic $\phi_{\mathrm{j}}$ for the batch of joints is calculated to be $10.9 \mathrm{mrad}$. SD is for the Standard Deviation of the batch of results, and is given by Mean $\times \mathrm{CV}$. Analysis therefore indicates that the SLS vertical deflection limit for the FRP cleated joint could be $L / 300$. This $L / 300$ limit is given in Fig. 9 by a solid horizontal line and, clearly, this EC0 determined limit is significantly below all, but $L / 360$, of the four limits in the load table on page 22 of Chapter 4 (Anonymous 2013a). For a nominally pinned joint a rotation of $17.8 \mathrm{mrad}$ (for $L / 180$ ) has been shown to be too liberal since FRP cracking can be present this deflection can be reached in practice. Clearly there will be severe FRP damage (at cleat tops) when the vertical deflection attained $L / 150$ (for a $\phi$ of $21.3 \mathrm{mrad}$ ). Even the lower SLS limit of $L / 250$ from the EUROCOMP Design Code and Handbook (Clarke 1996) could be unacceptable because durability will be impaired when cleats have delamination damage.

Based on an evaluation of the test results presented in Table 1 a mid-span vertical deflection of $L / 300$ can be proposed to ensure satisfactory performance during the service life. It is to be recognized that a SLS limit of $L / 300$ could be relaxed when the environmental conditions surrounding the FRP cleating are benign (i.e. there is minimal moisture/water to attack exposed glass fibres at the delamination crack surfaces (Zafari and Mottram 2012)). This more favourable serviceability condition could, for example, exist if the simple constructed frame is enclosed by, say weather protecting panelling.

\section{Joint tests with steel cleats}

The same test method was carried out with a batch of three nominally identical specimens having replaced the FRP cleats with steel cleats possessing virtually the same dimensions. Table 2 reports 
the results from the six steel joints using the same format as in Table 1. Because failure is different

431

432

433

434

435

436

and new, there is a need to develop a specific definition for what constitutes damage onset. As for the test series with the 10 joints with FRP cleats there follows a discussion on the moment-rotation results and what could be the SLS vertical deflection limit for a (simply supported) beam subjected to a uniformly distributed load.

\section{Defining damage onset with steel cleats is more complex than was the case with FRP cleating.} Because steel cleats are not the weak link, failure in the FRP occurs close to the web-flange junction in the pultruded column member. Because this initial damage is internal it could not be observed by visual inspection. In the absence of visible FRP cracking, damage onset was signalled by the first audible acoustic emissions emanating from the source of internal fracturing. Additional evidence for this approach to establishing $\phi_{\mathrm{j}}$ is that audible noises were found to coincide with a significant outward flexural deformation of the flange outstands at the top bolt level. This deformation was signalled by the commencement of nonlinearity in $M-\phi$ response. Damage onset is, therefore, specifically defined with steel cleating as the point on the $M-\phi$ curve when acoustic emissions were first heard, followed by measurement of considerable flexural deformation of column flanges. It is noteworthy that acoustic emission had previously been established from FRP joint testing (Mottram and Zheng 1999a) to be a reliable indicator for onset of FRP failure.

Figs. 10(a) and 10(b) show the jointing region in specimen Wmj203_2M16_ST1.3 before testing and after $M_{\max }$ had been attained. Comparing the two images shows that there was, at the end of testing, significant outward flexural deformation of the flange outstands level with the top bolts. The depth of the column at bottom bolt level $\left(h_{\text {(воттом })}\right)$ essentially remains constant, and is unaffected by the resultant compressive force from the moment generated by the prying action. Fig. 11 presents the variation in column depth $h_{\text {prying, }}$ due to prying action, corresponding to $M$. Column depth at the top bolt level is denoted by $h_{\text {prying(TOP) }}$ and is plotted with a solid line. The dashed curve in Fig. 11 is for column depth at the bottom bolt level, represented by $h_{\text {prying(воттом). The column depth at bottom bolt }}$ 
level of web cleat shows a marginal decrease of $0.1-0.2 \%$, as the moment approaches $M_{\max }$. When $M$ exceeds $1.4 \mathrm{kNm}, h_{\text {prying }}$ at the top bolt level is found to increase rapidly from 1 to $4 \%$ of the measured undeformed depth, $h$ (i.e., $202.4 \mathrm{~mm}$ ). This non-linear response is a signal of impending ultimate joint failure. In the three tests with a pair of steel cleat joints the maximum increase in column depth was found to be $1.05 \mathrm{~h}$.

Presented in Table 2 are the initial $\left(M_{\mathrm{i}}, \phi_{\mathrm{i}}\right.$ and $\left.S_{\mathrm{i}}\right)$, damage onset $\left(M_{\mathrm{j}}, \phi_{\mathrm{j}}\right.$ and $\left.S_{\mathrm{j}}\right)$ and maximum joint properties $\left(M_{\max }\right.$ and $\left.\phi_{\max }\right)$. The properties at damage onset were determined using the specific definition for steel cleating introduced above. $M-\phi$ curves for the six joints were found to remain linear to a mean $M_{\mathrm{i}}$ of $0.64 \mathrm{kNm}$. Because this joint property varies from 0.61 to $0.66 \mathrm{kNm}$ it has a relatively low $\mathrm{CV}$ of $4 \% . \phi_{1}$ is found to range from 3.2 to $4.6 \mathrm{mrad}$, giving a mean and $\mathrm{CV}$ of 3.8 $\operatorname{mrad}$ and $13 \%$ respectively. The batch of steel joints gave a mean initial rotational stiffness $\left(S_{\mathrm{i}}=\right.$ $M_{\mathrm{i}} / \phi_{\mathrm{1}}$ ) of $169 \mathrm{kNm} / \mathrm{rad}$, with a $\mathrm{CV}$ of $11 \%$, and the minimum and maximum stiffnesses are 144 and $194 \mathrm{kNm} / \mathrm{rad}$. At the onset of FRP damage in the column member the mean moment $\left(M_{\mathrm{j}}\right)$, rotation $\left(\phi_{\mathrm{j}}\right)$ and rotational stiffness $\left(S_{\mathrm{j}}\right)$ are $0.88 \mathrm{kNm}, 5.9 \mathrm{mrad}$ and $150 \mathrm{kNm} / \mathrm{rad}$, respectively. As established by their CVs being $\leq 10 \%$ these joint properties do not vary too much. The mean $M_{\max }$ and $\phi_{\max }$ are $1.7 \mathrm{kNm}$ and $42 \mathrm{mrad}$ with corresponding $\mathrm{CVs}$ of $8 \%$ and $51 \%$. The reasons for why there is considerable variation in reported $\phi_{\max }$ values in Table 2 are the same as for the detailing with the FRP cleating. To demonstrate that joint detailing with steel cleats can be classified as nominally pinned for their strength the mean $M_{\max }(1.72 \mathrm{kNm})$ is found to be $<12 \%$ of the estimated moment resistance of the section $(14.5 \mathrm{kNm})$ for the ULS failure mode of local (flange) buckling.

Moment-rotation $(M-\phi)$ curves for the Wmj203_2M16_ST1.2 joints are plotted in Fig. 12 (with slip rotation included) and Fig. 13 (with slip rotation compensated for). Both figures show that there is virtually a linear response to the damage rotation $\left(\phi_{\mathrm{j}}\right)$, which is characterised by loss of rotational stiffness and the increasing outward flexural deformation of the column flange outstands. After 
reaching $M_{\mathrm{j}}$ of $0.9 \mathrm{kNm}$ (as given by the solid circular symbols), the $M-\phi$ curves go increasingly nonlinear. The measured rotations from slippage were 1.1 and $0.6 \mathrm{mrad}$ at $\phi_{\mathrm{j}}$. With the slip rotation taken into account $\phi_{\mathrm{j}}$ for Left and Right joints were 5.3 and $6.5 \mathrm{mrad}$.

Specimen Wmj203_2M16_ST1.2 was unloaded and reloaded to determine the extent of permanent deformation. First unloading took place when $\phi$ approached $16 \mathrm{mrad}$ and gave a permanent rotation of $5 \mathrm{mrad}$ for both joints. Because of progressive internal material damage, it was hard to keep both joint rotations roughly the same. On reloading to the same (unloading) moment it was observed that $\phi$ increased to $35 \mathrm{mrad}$ on Left side whilst the Right side rotation stayed constant at $16 \mathrm{mrad}$. This change in joint response indicates that the Left joint was deteriorating more rapidly. This finding was confirmed by different permanent rotations of 10 and 5 mrad when Wmj203_2M16_ST1.2 was unloaded and reloaded again when the Left and Right $\phi s$ were 35 and 16 mrad. Unloading after $M_{\max }$ had been surpassed gave permanent $\phi$ s of 15 and $10 \mathrm{mrad}$.

Replacing cleats of pultruded FRP with structural steel gives a stiffer and stronger joint. As listed in column (6) in Table 2 the mean $\phi_{\mathrm{j}}$ with steel is almost half its mean in Table 1 for the FRP joints. Using a bar chart construction Fig. 14 presents the six joint $\phi_{\mathrm{j}} \mathrm{s}$ using the damage onset criterion for steel cleating. Following the presentation in Fig. 9 the SLS vertical deflection limit of $L / 180$ is given by a horizontal dashed line. The characteristic rotation for the steel joints is calculated to be $4.9 \mathrm{mrad}$, from Mean $-1.77 \times \mathrm{SD}$ and assuming the $\mathrm{CV}$ is known. For a simply supported beam with uniformly distributed load an end rotation of $4.9 \mathrm{mrad}$ results in a mid-span vertical deflection of only $L / 650$. The predicted characteristic value is seen to be below one-third of the recommend SLS rotation of $17.8 \mathrm{mrad}$ for a deflection limit of $L / 180$ taken from pultruder's Design Manual (Anonymous 2013a). It is moreover found to be less than half of the $12.8 \mathrm{mrad}$ recommended by the guidance in the EUROCOMP Design Code and Handbook (Clark, 1996). 


\section{CONCLUDING REMARKS}

510 Test results are presented for the moment-rotation characteristics of two batches of 10 and six

511 nominally identical (nominally pinned) joints having FRP or steel web cleats, respectively. In all

512 other respects the joint detailing and test method are identical. The variation found in rotational

513 properties from a batch of nominally identical joints shows why the testing was necessary. An

514 evaluation of the results was made using the key joint properties, the moment-rotation responses, the

515 failure modes, damage onset criteria and limits on vertical mid-span deflection for Serviceability

516 Limit State (SLS) design.

518 The main findings from the experimental study are:

519 - There are distinct failure modes for the batches of the joints with FRP and steel web cleats.

520 For the FRP situation failure is always due to excessive delamination cracking at top of the

521 cleats. When cleating is of structural grade steel FRP failure happens within the column

522 member as significant outward flexural deformation causes internal (non-visible) fracturing.

523 - It is noted that there is no mention of these failure modes in any of the pultruders' design 524 manuals (Anonymous 2013a; 2013b; 2013c). The authors recommend that all joint failure 525 modes and their design implications should be given for acceptable guidelines.

526 - The average initial rotational stiffness of $169 \mathrm{kNm} / \mathrm{rad}$ for the steel joints is found to be 527 double the stiffness of $76 \mathrm{kNm} / \mathrm{rad}$ for the FRP joints. In both cases, the average initial 528 rotation at which the moment-rotation response goes non-linear is similar, and is about 4 $529 \operatorname{mrad}$.

- The magnitude of slip rotation (at bolt holes) in the measured joint rotation was successfully minimised by having minimal bolt clearance holes for the beam-side cleat connections. Owing to 'off-the-shelf' M16 grade 8.8 bolts having a diameter in the range of 15.6 to 15.9 mm, tight-fitting bolting on specimen assembly was impractical. By compensating for slippage the test methodology ensured that reported joint rotations are due primarily to the deformation caused by the (damaging) prying action. 
- Using the statistical method in Annex D of Eurocode 0 the characteristic rotation at the onset of FRP damage (for material fracturing) is determined to be $10.9 \mathrm{mrad}$ for the batch of FRP joints. When a simply supported beam having span $L$ is subjected to uniformly distributed load, this nominally pinned joint rotation corresponds to a mid-span deflection limit of $L / 300$. It is found that the characteristic rotation is only $4.9 \mathrm{mrad}$ from the batch of steel joints. The corresponding deflection limit is only $L / 650$; under half that established with FRP cleating.

- It is recommended that the vertical deflection limits shall be carefully scrutinized by the EOR.

\section{Acknowledgements}

The authors wish to thank EPSRC (Connections and Joints for Buildings and Bridges of Fibre 
563 shapes, respectively. Skilled technical support from Mr Colin Banks (Civil Engineering), Mr Rob

564 Bromley (workshop) and Mr Graham Canham (photographer), in the School of Engineering, is 565 acknowledged as being invaluable to the quality and future impact of the research. 


\section{References}

Anonymous. (2000). Specification for Structural Joints Using ASTM A325 or A490 Bolts. Research Council on structural connections, American Institute of Steel Construction, Inc, Chicago, Illinois, USA.

Anonymous (2011). 'Code of standard practice for fabrication and installation of pultruded FRP structures,' ANSI standard, American Composites Manufacturers Association, $1^{\text {st }}$ Edition, Arlington, VA. July 29, 2011.

http://www.acmanet.org/cgi/CODE-OF-STANDARD-PRACTICE-DRAFT-ANSI-STANDARD.pdf

Anonymous. (2013a). The new and improved Pultex $®$ pultrusion design manual, Creative Pultrusions, Inc., Alum Bank, PA. (www.creativepultrusions.com/library.html) (Feb 8, 2013).

Anonymous. (2013b). Strongwell design manual, Strongwell, Bristol, VA. (www.strongwell.com/) (Feb 8, 2013).

Anonymous. (2013c). Fiberline design manual for structural profiles in composite materials, Fiberline Composites A/S, Kolding, Denmark. (www.fiberline.com/read-more-about-fiberlineonline-tools) (Feb 8, 2013).

Anonymous. (2013d). New Pre-Standard for Pultruded FRP Composites Funded thru ACMA Means Increased Applications, American Composites Manufacturers Association (ACMA) press release. //www.acmanet.org/pressreleases/2011/011711.html (Feb 8, 2013)

Bank, L.C. (2006). Composites for construction - Structural design with FRP materials, John Wiley \& Sons Inc., Hoboken, New Jersey.

Bank, L.C., Mosallam, A.S. and Gonsior, H.E. (1990). "Beam-to-column connections for pultruded FRP structures." In: Serviceability and Durability of Construction Materials. B. Suprenant, Editor, Proceedings ASCE First Material Engineering Congress, Denver, CO. American Society of Civil Engineers, 804-813.

Bank, L.C., Mosallam, A.S. and McCoy, G.T. (1992). "Design and performance of connections for pultruded frame structures." In: Proceedings of the 47th Annual SPI Conference, Composite Institute, Society for the Plastics Industry, Cincinnati, $\mathrm{OH}$, Session 2-B, 1-8. 
602 Bass, A.J. and Mottram, J.T. (1994). "Behaviour of connections in frames of fibre reinforced polymer

603 section.” Structural Engineer, 72(17), 280-285.

604

605

BS EN 1990:2002. Eurocode 0 - Basis of structural design. British Standards Institution, United 606 Kingdom.

607

608

BS EN 1993-1-8:2005. Eurocode 3: Design of steel structures - Part 1-8: Design of joints. British 609 Standards Institution, United Kingdom, 2005.

610

Clarke, J.L. (1996.). Structural design of polymer composites - EUROCOMP Design Code and 612 Handbook. E. \& F.N. Spon, London.

613

Daniel, R.A. (2003). "Environmental considerations to structural material selection for a bridge," In:

615 Proceedings of Lightweight Bridge Decks Conference, The Netherlands BRISK EVENTS 616 Technology Conferences, Leusen, pp. 19.

Gorenc, B.E., Tinyou, R. and Syam, A.A. (2005). Steel Designers' Handbook. University of New South Wales Press Ltd, Sydney, NSW 2052, Australia, 203-204.

Kulak, G.L., Fisher, J.W. and Struik, J.H.A. (1987). 'Guide to Design Criteria for Bolted and Riveted

Joints,' 2nd edition, John Wiley and Sons, New York, NY.

623

Mosallam, A.S. (2011). Design guide for FRP composite connections. Manuals of Practice (MOP) 102, American Society of Civil Engineers, Reston, VA., 624.

Mosallam, A.S., Abdelhamid, M.K. and Conway, J.H. (1994) "Performance of pultruded FRP connections under static and dynamic loads." J. Reinf. Plast. Comp., 13(5), 386-407.

631 Structural Design of Polymer Composites - EUROCOMP Design Code and Handbook, E. \& F. N. 632 Spon, London, 703-718.

634 Mottram, J.T. and Zheng, Y. (1999a). "Further tests on beam-to-column connections for pultruded 635 frames: Web-cleated.” J. Compos. Constr., 3(1), 3-11. 
637 Mottram, J.T. and Zheng, Y. (1999b). "Further tests on beam-to-column connections for pultruded 638 frames: flange-cleated.” J. Compos. Constr., 3(3), 108-116.

639

640

641

642

643

644

645

646

647

648

649

650

651

652

653

654

655

656

657

658

659

660

661

662

663

664

665

666

667

668

Mottram, J.T. (2004a). 'Determination of critical load for flange buckling in concentrically loaded pultruded columns,' Composites Part B: Engineering, 35(1), 35-47.

Mottram, J.T. (2004b). 'Friction and load transfer in bolted joints of pultruded fibre reinforced polymer section,' in Proceedings 2nd International Conference on FRP Composites in Civil Engineering - CICE 2004, sponsored by The International Institute for FRP in Construction (IIFC), The University of Adelaide, Adelaide, Australia, (2005), 845-850.

NA to BS EN 1993-1-1:2005. UK National Annex to Eurocode 3: Design of steel structures. Part 11: General rules and rules for buildings. British Standards Institution, United Kingdom.

Qureshi, J. and Mottram, J.T. (2012). "Moment-rotation behaviour of beam-to-column joints for simple frames of pultruded shapes." In: Sixth International Conference on FRP Composites in Civil Engineering - CICE 2012, sponsored by The International Institute for FRP in Construction (IIFC), Rome, Italy.

Turvey, G.J. (1997). “Analysis of pultruded GRP beams with semi-rigid end connections.” Compos Struct., 38(4), 3-16.

Turvey, G.J. (2000). "Moment-rotation tests on bolted end connections in pultruded GRP beamstests with stainless steel cleats and an assessment of their performance relative to GRP cleats." In: Proceedings of the Ninth European Conference on Composite Materials (ECCM 9: From Fundamentals to Exploitation), Brighton, UK.

Turvey, G.J. and Cooper, C. (2004). "Review of tests on bolted joints between pultruded GRP profiles.” P. I. Civil Eng-Str. B., 157(3), 211-233.

Zafari, B. and Mottram, J.T. (2012). "Effect of hot-wet aging on the pin-bearing strength of a pultruded material with polyester matrix." J. Compos. Constr., 16(3), 340-352. 